\title{
PERSPECTIVAS DEL TRABAJO SOCIAL EN PROCESOS DE PARTICIPACIÓN Y DESARROLLO EN EL CONTEXTO DE REESTRUCTURACIÓN DEL ESTADO \\ Ancizar Castro*
}

\begin{abstract}
RESUMEN
El articulo presenta una reflexión sobre los conceptos de la participación y del desarrollo desde los paradigmas que han predominado en las Ciencias Sociales en determinados momentos históricos. En él se concluye que el discurso y práctica de la participación y del desarrollo que se agencia desde el paradigma interaccionista son funcionales a las nuevas estrategias de acumulación de capital. Por lo anterior, se advierte a los Trabajadores Sociales para que asuman una postura crítica frente éste. Además, propone algunas ideas generales para abordar la participación y el desarrollo en el contexto de la descentralización del Estado, en la perspectiva de construir una nueva estética societal desde la construcción de hegemonía popular.
\end{abstract}

Palabras clave: Participación - Desarrollo

\begin{abstract}
The article introduces a reflection on the concepts of the participation and of development paradigms that they have preveiled in social sciencies in determining historic moments. It concludes that the discourse and practical of paricipation and of development that agency from the paradigm "interaccionista" is functional to the new strategies of acumulation from capital. For that, the article makes a warning to social workers so that they take critical posture opposite the mine. Also, it proposes some general ideas in the context of no central state, in the perespective of constructing a new social aesthetic from the construction of popular hegemony.
\end{abstract}

Key words: Participation - Development

n los actuales momentos la presencia en el discurso de las Ciencias Sociales y en la institucionalidad imperante de términos como lo local y/o comunitario, la participación y el desarrollo, cobran importancia en el campo propositivo del que-hacer profesional del Trabajador Social. Situación que nos invita a reflexionar sobre el cómo se han pensado y abordado dichos conceptos, pues dependiendo del marco de referencia teórico- conceptual dominante que ha habido en cada época, se traza una normatividad que pretende "moldear" la pulsión libidinal de los individuos para que sea funcional a un orden social establecido desde el poder hegemónico.

* Docente Escuela de Trabajo Social y Desarrollo Humano. Universidad del Valle. 
Tomemos por ejemplo la participación: nos es imposible hablar y alabar sus bondades en abstracto, ya que ésta y los procesos sociales que desembocan en una acción colectiva en un determinado momento y lugar (espacio-temporalidad), hay que situarlos en el contexto de la dominación social, este último determinado por la posición diferencial que tienen los diversos actores sociales respecto a las fuentes generadoras de poder, que Tofler (1995) sintetiza en riqueza económica, fuerza coercitiva y conocimiento.

De esta manera, el concepto de la participación para los sectores dominantes se ha entendido y abordado como una forma de concreción y legitimación de un orden social dado, en el que se limita teóricamente su alcance, en aras de mantener el interés general sobre el particular, en un contexto en el que la desigualdad y degradación tanto material como inmaterial de la población humana como de la no humana, es una constante con tendencia a agudizarse. Por el contrario, para los sectores dominados, la participación se piensa como un acto voluntario que debe instalarse en el nivel de las decisiones, lo que debe llevar necesariamente a una reconfiguración de estas relaciones de poder asimétricas, ya que lo que está en juego, si de lo que se trata es de participar para decidir, es el día por-venir.

A manera de conclusión diríamos que la participación como concepto y práctica, se "mueve" fundamentalmente en el terreno de lo político, el que se cimienta en la construcción de un determinado orden social. En el sistema capitalista, es el Estado, quien ha sido el principal artesano del mismo (todo orden incluye y excluye), por eso políticamente, "siempre" se ha necesitado incluir a la población (usted participa y yo decido) para que de esa manera legitime un estado de cosas dadas para un momento histórico particular.

Brevemente, analizada la injerencia de un paradigma sobre un concepto, abordemos suscintamente como las Ciencias Sociales han pensado especialmente la participación y el desarrollo, a través de los distintos momentos históricos que han vivido nuestras sociedades. Vargas (1994), Trabajador Social y Politólogo, sostiene que de acuerdo al paradigma dominante, se ha desprendido una manera particular de entender y valorar la participación, lo que no se da solamente a este nivel, sino que ha contribuido a orientar las políticas públicas tanto nacionales como internacionales. Obviamente, lo que nos parece mas importante, es que han condicionado ideológica e intelectualmente las lecturas que se trazan sobre la realidad, pues un paradigma contribuye a prefigurar una realidad determinada y por lo tanto incita a obrar en consecuencia.

\section{BREVE ITINERARIO DE LOS PARADIGMAS DE LAS CIENCIAS SOCIALES Y SU ENFOQUE SOBRE LA PARTICIPACIÓN Y EL DESARROLLO}

Argumenta el mencionado autor, que en los años cincuenta primó una mirada desde el paradigma estructural-funcionalista; que entendió el desarrollo como un proceso de modernización económica por la vía de la industrialización, donde se veía a las sociedades tradicionales y sus valores como un obstáculo para alcanzarlo. En esta perspectiva se entendió la 
participación como un ejercicio controlado y tutelado por el Estado, pues éste, en términos políticos, era el responsable y encargado de orientar "a la tripulación societal" hacia la meta del desarrollo.

En los sesenta, tomó fuerza el Marxismo-Estructuralismo, desde esta perspectiva se concibió el desarrollo como un proceso de liberación antiimperialista y anticapitalista, en el que se consideró como precondición necesaria romper con estas relaciones, para que se diera el desarrollo de las fuerzas productivas, sin replantear la concepción antropocéntrica y utilitarista que se promovió desde Occidente para abordar la relación fundamental Naturaleza-Población. Igualmente, se pensó el Estado Central como el encargado de trazar los parámetros para dicho propósito, bajo la guía de las élites revolucionarias, quienes se creían que eran los mas indicados para interpretar las expectativas y necesidades de la población. Durante este período la participación estuvo relegada a ciertos niveles de control y defensa de los derechos colectivos sobre los individuales.

De los ochenta hasta nuestros días, predomina una visión interaccionista, que piensa el desarrollo como producto de la competencia de los intereses individuales, bajo el supuesto que la suma de éstos contribuye a construir el interés colectivo.

Los requisitos para alcanzar el desarrollo, descansan en las supuestas virtudes de la competencia. De esta manera se piensa como idea - fuerza que el Estado no debe intervenir en la regulación de la sociedad, sino más bien debe estimular y desarrollar la iniciativa privada en todos los campos, lo que por sí solo redundará en beneficio de todos (liberalismo económico). En este enfoque se piensa entonces la participación como un elemento fundamental para agenciar procesos de desarrollo en varias dimensiones; en lo económico, la iniciativa privada como soporte vital del modelo de desarrollo. En lo político se enfatiza su utilidad para avanzar en la profundización de la democracia participativa y en lo social, se concibe como tabla de salvación para suplir las carencias que el Estado no cubre, especialmente en lo referido a la satisfacción de las necesidades Básicas. Sin embargo, en esta perspectiva, el Estado se abroga el derecho de monopolizar las decisiones estratégicas de amplia repercusión nacional.

\section{Contexto de la realidad colombiana en el pasado reciente}

No es suficiente señalar como se ha pensado la realidad para intervenirla, sino que se hace necesario referenciar el contexto socioeconómico y político (que aquí presentaremos de manera muy esquemática) para reconocer desde dónde se están planteando dichos conceptos, para definir por un lado, sus limitantes y alcances para transformar la realidad social y por el otro, proponer una discusión que intente lecturas más críticas y efectivas que nos permitan en nuestro ejercicio profesional como Trabajadores Sociales, avanzar en la construcción de una sociedad más libre y justa.

Es así como en Colombia a finales de los años ochenta era común entre los Cientistas Sociales afirmar que nuestra sociedad estaba viviendo una gran crisis, caracterizada por un modelo de desarrollo que traía consigo entre otros aspectos: 
- Desigualdades socio-económicas regionales, producto de la concentración de las acciones del Estado en áreas geográficas donde se han consolidado procesos productivos. Como es el caso de las grandes ciudades (triángulo de oro) Cali, Medellín y Bogotá.

- Rigideces fiscales caracterizadas por una administración centralizada y burocratizada, de espaldas a otras realidades locales y regionales.

- Alto nivel de insatisfacción de las necesidades vitales de una gran mayoría de la población colombiana

- Deslegitimación estatal, bajo la oleada de descontento popular, manifestado por el surgimiento de movimientos sociales en la década de los ochenta, que giraron en torno a la satisfacción de dichas necesidades.

- Desarrollo económico con un progresivo deterioro ambiental, producto de una concepción desarrollista fundamentada en la inagotabilidad de los recursos naturales.

Estos factores, pusieron en evidencia la poca viabilidad de el modelo dominante de desarrollo, que ha reinado entre nosotros, desde los años cincuenta. Este estado de cosas exigieron la búsqueda de propuestas de desarrollo para salirle al paso a dicha crisis. Se impulsaron de manera sistemática y gradual, desde la década de los años ochenta, procesos de modernización del Estado (funcional al nuevo patrón Neoliberal de acumulación de capital) a través de medidas ya conocidas por todos nosotros, tales como:

- Transnacionalización de la economía y la política, con eje en el mercado mundial.

- Privatización de las empresas estatales.

- Redefinición del papel del Estado en la regulación de la economía (énfasis al interés particular).

- Descentralización de los procesos productivos.

- Producción a destajo.

- Desmonte del Estado benefactor.

- Lo sectorial manejado cada vez más por lo transnacional.

- Regulación Estado/ sociedad privilegiando la lógica territorial.

Desde este enfoque se promueve la descentralización político-administrativa y fiscal, en la que el Estado por un lado, piensa lo local y lo regional como pieza fundamental para recuperar su legitimidad y por el otro, el capital los concibe como eje preponderante para su relanzamiento de acuerdo a su nueva estrategia de acumulación Posfordista. Todo esto ha venido enmarcado en un discurso de democracia participativa, en el que se estimula la participación (con mas de un centenar artículos en la constitución/91) y se convoca a dichos entes territoriales y/o comunidades a que elijan sus gobernantes, elaboren sus planes, implementen las políticas públicas y resuelvan sus propios problemas sin esperar nada del Estado, bajo el pretexto que son ellos los directos responsables de su desarrollo.

Teniendo en cuenta este contexto, observamos como el paradigma interaccionista se torna dominante en la explicación y análisis de los fenómenos sociales y de los problemas del desarrollo que se presentan hoy en día en nuestras sociedades contemporáneas, dándose cierta correspondencia 
en lo analítico, conceptual e ideológico con los procesos de neoliberalismo económico y social, que se comienza a consolidar a nivel global. Por lo tanto no es de extrañar el "culto exacerbado" que le asignan algunos teóricos sociales a dicho proceso de modernización estatal como posibilidad real para salirle al paso a la crisis endémica que padecen nuestros pueblos.

\section{Restricciones de la democracia participativa promovida desde el Estado}

El peligro que implica seguir este paradigma dominante sin advertir sus verdaderas consecuencias para nuestras sociedades, como es la de sobredimensionar la participación social en el ejercicio del "poder local”, hace necesario tener en cuenta algunas restricciones de la democracia participativa, tales como las que señala Vargas (1994):

- La participación estimulada por el Estado, tiene la características de ser tutelada controlada y restringida, pues en ella se busca que los actores populares organicen sus demandas de acuerdo al esquema estipulado por el Estado, ya sea por la vía bipartidista o la intermediación tecnocrática.

- Se invita a participar en la implementación de las políticas sociales, pero se restringe en los aspectos fundamentales que tienen que ver con la orientación global del desarrollo tales como; la definición en las políticas macroeconómicas (que la define la tecnocracia en concordancia con el capital transnacional), las políticas del exterior, las del orden público, etc.

- Se logra observar también que estas convocatorias de la participación se ubican en espacios políticos y sociales cada vez más divididos, fragmentados sin una aparente articulación entre si y con el todo. Por ejemplo a los campesinos se invita a participar en los consejos municipales de desarrollo rural, a los usuarios en la gestión de los servicios públicos, a la comunidad a resolver problemas en su localidad, a los ciudadanos a fiscalizar la gestión de los funcionarios públicos. Es decir, se abre cada vez más la brecha entre lo local con lo global, lo público con lo privado, lo sectorial con lo territorial, sin establecerse ningún tipo de articulación con propuestas mas integradoras.

\section{Con respecto al ejercicio de la participación en los procesos Municipales}

Se observa, según Velasco (1995):

- Poca voluntad política de los alcaldes para posibilitar procesos reales de participación ciudadana y comunitaria, donde quedan reducidos a un mero formalismo legal.

- La participación comunitaria, se ha reducido al trabajo de obras de infraestructura, lo que ha sido funcional para el Estado, disminuyendo costos de inversión.

- Poca cultura de la participación ciudadana en la población.

- Y también miradas restringidas del desarrollo a la satisfacción de necesidades básicas, sin estrategia política que transcienda lo local. 


\section{PERSPECTIVA DEL TRABAJO SOCIAL EN LA PARTICIPACIÓN Y EL DESARROLLO}

Ante este panorama, parece que nos encontramos frente a un proceso social en el que se encuentran dos dinámicas divergentes y convergentes a la vez, por un lado esta la necesidad de los sectores dominantes de producir y reproducir socialmente su propuesta neoliberal de desarrollo -que para nosotros lo que pretenden es administrar la crisis y no superarla, pues estamos convencidos que las estrategias desarrollistas y neoliberales han fracasado como propuesta para construir una sociedad satisfactoria para todos- y por el otro, está la dinámica propia de los movimiento sociales, (locales y/o regionales) que deben ser los actores básicos para construir propuestas alternativas de desarrollo.

La pregunta que nos surge entonces, es ¿ cómo avanzar en la construcción de un pensamiento utópico-posible tejido orgánicamente con los sectores populares, que nos permita prefigurar y materializar una realidad más libre y justa para todos, en el actual contexto de la reestructuración del capital y del Estado?

Partamos de una premisa, que la participación social no es una dádiva de los sectores dominantes, ni un mero ejercicio de institucionalización de las luchas sociales. Por lo tanto creemos, retomando lo planteado por Coraggio (1989) que se debe avanzar en la construcción de una hegemonía popular -sin caer en dictaduras- que sustituya la anterior (Neoliberal) y construya una nueva estética societal a partir de los espacios creados desde el Estado para el ejercicio de la participación y de la democracia, esto implica (teniendo en cuenta las restricciones señaladas), crear e imaginar nuevos sentidos y contenidos que orienten nuestro accionar social, para lo cual proponemos:

- No seguir pensando que las comunidades o los movimientos particulares locales pueden constituir por sí solos el sujeto capaz de transformar el Estado y la sociedad, porque los problemas de la democracia y el desarrollo, transcienden a una cuestión nacional e internacional, la que no se puede seguir reduciendo al ámbito exclusivamente local y/o comunitario. Pues construir "una" hegemonía popular no debe quedarse en el planteamiento de necesidades inmediatas particulares, ya que se requiere de trascendencia, prefigurando horizontes políticos "consentidos" colectivamente. Lo que implica articular nuestro trabajo intelectual con los sujetos (movimientos sociales) que viabilicen la construcción de dicha utopía, evitando de esta manera su expontaneismo. En esta perspectiva vemos "el arte de la planificación" en y para los procesos sociales de desarrollo comunitario en correspondencia con lo territorial local-regional, como una gran posibilidad para avanzar en dicha dirección.

- El trabajador social y la dinámica de los procesos sociales de desarrollo que acompañe, deben interiorizar la convicción que la lucha social debe encarar el marco institucional dominante como ejercicio para construir un nuevo modelo de gobernar. Ya que una propuesta alternativa de desarrollo requiere de dichas formas para su sustentabilidad en el tiempo y en el espacio. 
- Romper con la división entre economía y política, pues pretender construir el propio desarrollo desde las localidades (premisa dominante en el discurso contemporáneo) es plantearse un proyecto sin sujeto, debido a que la dinámica local está supeditada a mandatos globales, con lo que la autonomía a este nivel, queda reducida a una mera formalidad. De esta manera la autonomía política solo es posible con un control de la economía, para avanzar en una transición efectiva en el autogobierno de los pueblos, lo que nos exige "tejer" articulaciones entre los diferentes niveles de "organización territorial" pues estas dimensiones económica-políticas transcienden las rígidas fronteras político-administrativas trazadas por el poder.

Por último, consideramos que se debe romper con las dicotomías que nos ha hecho creer la racionalidad dominante; mundialización-localización, dependencia-autodependencia, estructurasindividuos, masas-persona, homogenización-diferenciación, razón-sin razón (sentidos) etc. Pues como dice Coraggio (1989) "una teoría de la sociedad existente o prefigurada, debe incluir las complejas leyes que rigen el funcionamiento de nuestras sociedades en el mundo contemporáneo, en el que en ningún momento se puede reducir su interpretación a una combinatoria de elementos viejos o nuevos", debemos avanzar entonces en crear miradas holísticas que nos permitan aprehender, comprender la realidad como un todo y obrar en consecuencia.

\section{REFERENCIAS BIBLIOGRÁFICAS}

BALLESTEROS RAMÓN y CASTRO NESTOR "Participación en lo regional y lo local” en Participación ciudadana, ESAP, Santafé de Bogotá, 1997.

CASTRO ANCÍZAR y OTROS-Equipo de Investigación "Descentralización y Gestión del liderazgo indígena", "participación ciudadana y democracia local”, Editorial CENCOA, Cali, Marzo 1997.

CORAGgIO JOSÉ L. "Poder local, ¿poder popular?”. Descentralización y poder local, Textos II, Ciudad de Quito, 1989.

CORAggio josé L. Territorios en transición; critica a la planificación regional en América Latina, Ciudad Quito, 1987.

FALS BORDA ORLANDO "El nuevo despertar de los movimientos sociales", en Participación comunitaria y cambio social en Colombia, Villa de Leyva, 1986.

GONZALEZ ESPERANZA "Manual sobre participación y organización para la gestión local" Foro, Cali 1995.

TOFFLER ALVIN “La vida en la economía supersimbolica”, El cambio del poder, Plaza y Janes, 1990.

VELASCO IVÁN "Sociedad local, la política social y el cambio político institucional”, en Prospectiva No 2,

Escuela de Trabajo Social, Cali, Universidad del Valle 1995. P 29-35.

vargas Alejo. Participación Social, Planeación y Desarrollo Regional, Universidad Nacional, Bogotá, 1994.

Recibido en febrero 16 de 2004

Aprobado en mayo 10 de 2004 